onate. After $1 \mathrm{hr}$. , more catalyst $(0.2 \mathrm{gm}$.$) was$ added, and the reaction was complete $30 \mathrm{~min}$. later, with an almost theoretical uptake of alkali. The filtered solution was reduced to half volume, treated with charcoal, and made acid to congo red with hydrochloric acid. The hydrated glucuronide was filtered off and recrystallized from 50 per cent $(\mathrm{v} / \mathrm{v})$ aqueous ethanol and then from water : yield $0.95 \mathrm{gm}$. (54 per cent). After drying at $105^{\circ}$ over phosphorus pentoxide, the hemihydrate ${ }^{2}$ had corrected and mixed melting points with a biosynthetic specimen of $139-140^{\circ}$, and $[\alpha]_{D}^{22}-119^{\circ}$ in water $(c, 0.25)$ : on acid hydrolysis 4-methylumbelliferone was obtained, melting point and mixed melting point $187-188^{\circ}$. Mead et al. ${ }^{2}$ give a melting point of 139 $140^{\circ}$ (decomp.) for the hemihydrate of the biosynthetic glucuronide, and $[\alpha]_{D}^{23}-105^{\circ}$ for the completely hydrated compound.

Grateful acknowledgment is made to Prof. R. T. Williams and Dr. D. Robinson for specimens and unpublished results.

C. A. Marsh

G. A. Levvy

Rowett Research Institute,

Bucksburn,

Aberdeenshire.

March 29.

${ }^{1}$ di Somma, A. A., J. Biol. Chem., 133, 277 (1940).

${ }^{2}$ Mead, J. A. R., Smith, J. N., and Williams, R. T., Biochem. J., 61, 569 (1955).

${ }^{3}$ Marsh, C. A., J. Chem. Soc., 1578 (1952).

4 Tsou, K.-C., and Seligman, A. M., J. Amer. Chem. Soc., 75, 1042 (1953).

${ }^{5}$ Robinson, D., and Williams, R. T., Biochem. J., 61, v (1955).

\section{Phase-Change in 1,2,4,5-Tetrabromobenzene investigated by Pure Quadrupole Resonance}

Ir is the purpose of this communication to mention a result of a type which we believe to be hitherto unreported, which we obtained when the temperature dependence of the bromine-81 pure quadrupole resonance at about $240 \mathrm{Mc}$./s. in 1,2,4,5-tetrabromo. benzene was investigated. Here, on raising the temperature above $20^{\circ} \mathrm{C}$, there is as usual a linear decrease of frequency. However, a very sudden discrete drop occurs at $46.5^{\circ} \mathrm{C}$, after which there is again a linear decrease. On then reducing the temperature, the increase of frequency is linear as far as $33.5^{\circ} \mathrm{C}$., where there is a sudden discrete rise, the frequency returning to the original line and completing a hysteresis loop.

The experimental results are shown in Fig. 1. The temperature coefficients of frequency are $-3.9 \times$ $10^{-5} /$ deg. C. and $-5.9 \times 10^{-5} / \mathrm{deg}$. C. for the upper and lower straight line portions respectively. The frequency jump is of the order of 1.5 parts in $10^{3}$. It is interesting to note that the temperature enefficient at temperatures above the discontinuity is of the order usually found in compounds where bromine is attached to the benzene ring, while that at temperatures immediately below is about 35 per cent lower.

The resonance was obtained by means of an externally quenched frequency-modulated super-regenerative oscillator using $\mathrm{a}$ cathode-ray oscillograph display. A push-pull arrangement was used employing type 955 'acorn' triodes, the sample being placed in a tuned

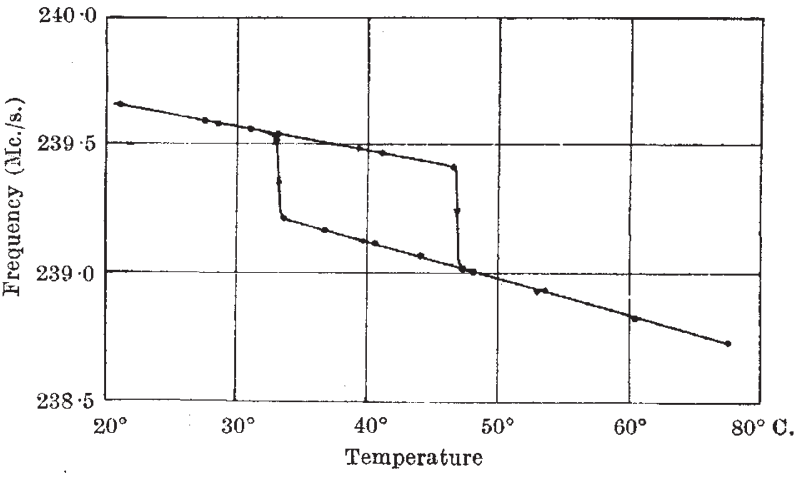

Fig. 1. Frequency of bromine-81 pure quadrupole resonance in $1,2,4,5$-tetrabromobenzene as a funetion of temperature

coil at the far end of the anode lines. A simple oven surrounds the specimen. Comparison between frequency measurements made with slowly rising and slowly falling temperatures indicates that the error of temperature measurement is $\pm 0.2^{\circ} \mathrm{C}$.

Frequency measurements were made by adjusting the amplitude and frequency of quench so that the resonance appeared as a single peak. This was then located at the centre of the cathode-ray oscillograph display. The sweep and quench were then switched off, and the frequency of the oscillator measured by obtaining zero beat with a harmonic of a calibrated wave-meter, type $B C-221-C$, detected by means of a G.E.C. very high frequency panoramic receiver, type BRT-652. The calibration of the wave-meter was set for each reading by means of the $2 \mathrm{Mc} / \mathrm{s}$. crystal incorporated in the receiver. This was, in turn, checked against a B.B.C. transmission at $94 \cdot 3 \mathrm{Mc} / \mathrm{s}$., which afforded a sufficiently accurate standard at a convenient frequency. This system of measurement gives an error of about \pm 5 parts in $10^{5}$, which includes that of setting the oscillator exactly upon the quadrupole frequency.

Thanks are due to Mr. D. Pardy for carrying out the measurements.

Research Division, Signals Research and

Development Establishment

(Ministry of Supply),

Christchurch, Hants. June 12.

\section{Factors affecting the Permanency of Paper: Tests with Labelled Sulphur}

PAPERs of good quality and high alpha-cellulose content can be kept under suitable storage conditions for several centuries. There are, however, differences of opinion on factors affecting storage, and a recent investigation by Langwell ${ }^{1-5}$ claims that even goodquality papers can become brittle at the edges. He stated that this attacked portion of the paper in old documents and books has a scorched appearance resembling the product of the reaction between cellulose and strong acid. Analyses of these old papers reveals a high sulphate content indicative of attack by sulphuric acid from the atmosphere.

The concentration of sulphur dioxide in industrial atmospheres is of the order of 0.5 part per million ${ }^{6}$, and Langwell has suggested that catalysts in the paper accelerate the conversion of this sulphur 